\title{
关于夷平面
}

\section{崔之久 李德文 伍永秋 ${ }^{(4)}$ 刘耕年}

( 北京大学城市与环境学系, 北京 100871; 44北京师范大学环境演变与自然灾害国家教委开放实验室, 北京 100875)

摘要 夷平面包括准平原、山麓面和刻蚀平原。三者成因和分布不同, 但其间并无不可逾越的 障碍. Budel 就花岗岩区提出的“双层夷平面”理论也基本上适用于我国南方灰岩区, 他把风化 壳作为夷平面上部层, 对夷平面形成环境和各种风化矿产形成条件的研究均具有重要理论与 实践意义. 近年来在研究青藏高原隆升幅度和速率时, 国外同行怀疑利用古生物化石等作为 依据的可靠性, 只承认夷平面原始高度作为陆地抬升幅度的可靠标志. 总之, 夷平面的研究是 一个古老而又永远年青的课题.

\section{关键词 夷平面 准平原 山麓面 刻蚀平原}

\section{1 历史回顾}

一个世纪以前, 地貌学的前辈们曾就准平原概念和特征展开过执着的探索和热烈的争论. 自 Davis ${ }^{[1]}$ 提出准平原 (peneplain)、Gilbert ${ }^{[2]}$ 提出山麓面( pidement) 始, 已经历了一个世纪, 但 这些问题仍然是当今地貌学中最重要的基本理论问题之一.

生命循环信息, 这些信息在通常的化石调查中是不可能达到的. 以往, 对于前寒武纪缺少化石 记录的通常解释是, 那时的动物柔软、微小不能保存为化石. 现在, 这样的化石开始出现了, 特 别是陡山沱期的磷酸盐不同凡响, 它们揭示了许多重要信息.

晚前寒武纪末至早寒武纪初的全球性成磷事件, 为我们提供了一个保存早期后生动物软 组织和胚胎发育的化石库, 对于探讨寒武纪大爆发的起因以及与前寒武纪生命演化的关系提 供了新线索. 总之, 古胚胎化石是寒武纪大爆发的历史见证, 早期后生动物胚胎学是一门研究 过去的科学, 但是它将具有灿烂辉煌的未来.

\section{参 考 文 献}

1 Bate R H. Phosphatized ostracodes with appendages from the Low er Cretaceous of Brazil. Palaeontology, 1972, 15(3): 379 $\sim 393$

2 Zhang X G, Pratt B R. Middle Cambrian arthropod embryos with blastomere. Science, 1994, 266: 637 639

3 Bengtson S, Yue Z. Fossilized metazoan embryos from the Earliest Cambrian. Science, 1997, 277( 5332): 1 645 1648

4 岳 昭, Bengtson S. 寒武纪大爆发中的磷酸盐化胚胎化石. 科学通报, 1998, 43(17) :

5 Begtson S. Animal embryos in deep time. Nature, 1998, 391: 529 530

6 Xiao, S, Zhang Y, Knoll A. Three_dimensional preserveation of algae and animal embryos in a Neoproterozoic phosphorite. Nature, 1998, 391: 553 558

7 Ker R A. Pushing back the origins of animals. Science, 1998, 279: 803 804

8 Li C, Chen J, Hua T. Precambrian sponges with cellular structures. Science, 1998, 279: 879 882 
“夷平面” 这一概念包括准平原、山麓面及联合山麓面( 也叫山麓剥蚀平原和山麓侵蚀面平 原 (pediment and pediplains) ) 和刻蚀平原 (ethplains) ${ }^{[3]}$. 虽然准平原一词从一提出来就遭到批 评、反对 ${ }^{1]}$, 但在内容广泛的有关夷平面的讨论中, 它仍占据“老大”的地位.

\section{1 准平原}

可以说, 这是一个引起较多争论和混乱的词. 100 多年过去了, 作者只能说, 在可见的将 来还是如此. 人们一再说应放弃这个含义不确切的名词. 而又一再地给以关注. 真是欲罢不 能. 理想地、非完全的夷平面可以归结于近平原 ( almost-plains) 或“准平原”. 但究竟离完全 的水平面多远才能被称为“近平原”或“准平原”呢? 或者说一个夷平面接近平原到什么程度才 能被如此定义呢? 总的来说, 不能认为一个起伏过大的地面是一个夷平面. 但这里重要的不 是起伏的高度而是坡度值或坡降值. 正如文献[ 4] 中所强调的, 高差可以有 $1000 \mathrm{~m}$, 但坡降 只有 $1 \%$, 即 $1000 \mathrm{~km}$ 升高约 $1000 \mathrm{~m}$. 其坡度的界线是地面土壤层向下蠕动的休止角, 为夷 平坡度的上限值, 如 Budel ${ }^{[5]}$ 在德干高地所界定的 $2 \%$ 。而粗粒倒石堆的坡度角 ( $35^{\circ}$ 或略小) 若大于夷平作用终止阶段的上限值则不能接受 ${ }^{[3]}$. 此外还有坡度组合问题, 它涉及夷平面作 用、地面上的沉积盖层(如风化产物和后来的冲积产物等) 和侵蚀结果等问题.

准平原 (也可以说夷平面) 的形成动力早期被认为是海洋营力 ${ }^{[6]}$. 从理论上讲, 如果不考 虑时间和海拔的限制, 海浪可以将任何陆地破坏, 直至整个陆地消失. 相比之下, 流水虽在地 面塑造中有可观的作用, 但与海洋营力相比则小多了. Davis ${ }^{[7]}$ 则将强调重点移到了大陆营 力, 他强调流水的功效, 并创立了“准平原”一词. 后来受美国西部考察者 Gilbert 的影响, Davis $^{[8]}$ 综合推导出一系列地貌演化并最终发育成准平原的学说, 这就是他的“地理循环” ( geographical cycle). 由于完全的夷平需要无限长的时间, 因此 Davis 承认在有限时间里只能达 到一定阶段, 这就使准平原一词产生了双层含义一一即在形态上近似于平原 (almost - plain) 和在过程上接近于循环结束( 保有低起伏和缓坡的地面)。到本世纪初期( 1910 1920), Davis 在美国阿巴拉契亚山地看到不同岩性的山顶显示出一致的高度, 他认为是原来的准平原被抬 升切割的结果, 并称之为 “上升的准平原”. 在遭到反对时他用此及其他材料进行了强有力的 辩驳. 由此, Davis 的 “准平原” 从事实到概念是有立足之处的, 想推翻它是不容易的, 而也只能 不断地补充它, 完善它. 后来 Penck ${ }^{[9]}$ 进一步指出, 随着地块抬升速率的时空变化, 将产生一 系列不同于 Davis 所看到的地貌形态, 所以他主张山前梯地学说.

作者认为, 准平原确实存在或存在过, 虽然并不像想象中那么完美. 正如 Davis ${ }^{[10]}$ 自己 所说, “要使名词永远完全符合于它们的定义, 这无疑是困难的. 很少可能把名词限于一个意 义”. 此外按 Davis 本义, “剥蚀” 和“夷平”有明显的区分. 前者主要指幼年期和壮年期进行的 过程, 当时河流下切、拓宽, 基岩裸露, 受到风化、冲刷和剥蚀, 大量岩屑被带走; 后者则更恰当 地用于循环后期那些较缓慢的过程, 其结果是平衡坡面被蚀成更缓的角度, 剥蚀将系统地转化 成夷平 ${ }^{[10]}$. 据认为现在地球上任何地方都不存在现代意义的广泛的准平原, 但人们相信有许 多古准平原残留在山区, 是由不同地理循环所造成的.

\section{2 山麓面和联合山麓面}

在上述夷平面的类型中, 争论最少的是山麓面和联合山麓面. 几乎大家都同意山麓面的 存在, 因为它有明显的识别特征并且在许多地区仍在形成. 它从山脚向下方倾斜, 一直均夷至 当地的侵蚀基准面 (如内陆湖泊) 或更广泛的基准面 (较大型内陆水系), 是山麓带的一个组成 
部分, 规模可大 (联合山麓面) 可小 (局部山麓面). 若认为它仅包括侵蚀部分, 则不包括冲积扇 和干盐湖的沉积因子, 但事实上冲刷盖层常常存在 . 若认为它同时也包括上述沉积部分, 则 它也可以是一种蚀积共同体. Adams 提议由法文 Glacis( 缓斜坡) 代替 pediment. 这两个词都 来自建筑学: glacis 是建筑学上一种分级到低角度的坡, 形成一个围绕着城墙根的石帷裙, 共同 组成一个从直角的城墙向外逐渐变缓的有坡度的地面, 以使敌人在城下无隐藏之处. 它与自 然地面有一定的几何相似性. 故易于被接受. 而 Pidement 是建筑上描述希腊神庙门椐上的三 角楣饰的一部分，它高高在上, 与自然地面毫无几何相似性, 故易造成混淆.

\section{3 刻蚀平原}

刻蚀平原的“刻蚀” 是像艺术上用酸腐蚀金属板上一部分而刻蚀成画一样,即风化又去掉 风化产物(剥蚀、刻蚀), 从而暴露出未风化的基岩面, 产生类似刻蚀板( ethplate) 效果那样的 “刻蚀平原”, 在国内文献中大量基岩剥蚀面的描述当属此一类型. 但正如 Adams ${ }^{[3]}$ 所提出, 若基岩上风化产物很厚, 即风化前锋低而达到风化速率与冲刷速率平衡时( 如覆盖型 Karst 区 作者注), 表面虽与剥蚀作用有关而基岩面并未暴露, 这还能被认为是一个“刻蚀平原” 吗? 此外, Adams 还认为, 刻蚀平原可望从其他夷平面发展而来, 但不是从起伏大的山地逐渐夷平 而来. 可见对刻蚀平原的理解是有争议的.

Adams 在评论准平原、联合山麓面和刻蚀平原三者的关系时, 曾引用澳大利亚中、西部的 例子. 除深度红色风化壳的存在是各种夷平面上的共同特征外, 对不同类型夷平面之定义及 彼此之间关系、Davis 准平原观点、准平原是否是唯一的夷平面以及夷平面是否仍在发育等问 题都存在争议 ${ }^{[3]}$. 由此可见, 一个世纪以来在夷平面研究中虽取得了重大进展, 但在更深层 次上又提出了许多新的问题.

回顾夷平面研究历史, 在本世纪 60 70 年代, 夷平面研究确有兴盛之势. 这既与国际科 学组织 (国际地理联合会环大西洋夷平面与阶地委员会等) 的活动有关, 也与当时新的地貌概 念出现有关, 如 King 的山麓面理论、Budel 的“双层面”思想、多成因夷平面学说 ${ }^{[1]}$ 以及数学和 统计方法、计算机制图等方法的运用. 其中山麓化作用拥有较多的支持者, 认为它不仅存在于 半干旱气候区, 也出现在温和气候区及亚热带气候区. 而根据多成因面思想, 可以追索埋藏的 古剥蚀面并进行古地貌分析, 结合相分析、建造分析等手段可以恢复古地貌. 这对油气田勘探 具有重要意义 ${ }^{[12]}$.

$\mathrm{King}^{[13]}$ 提出在任何构造和气候条件下后生侵蚀旋回地貌形态同源性的观点, 以替代 Davis 的形态侵蚀循环. 同时, 法国地貌学家 Baulig ${ }^{[14]}$ 发表的大量文章, 批判性地分析了 Davis、Penck 和 King 的观点, 他认为目前地表存在形成准平原和联合山麓面的条件, 前者位于 温湿气候区, 后者见于干旱气候条件下. Baulig 还提到, 准平原作用与选择性剥蚀关系密切, 故在岩石坚硬程度不同的地区不可能形成真正的准平原, 而联合山麓面则不太讲究岩石性质, 它可以剥蚀不同岩性. 作者认为, 准平原和山麓面的发育还是用创始人的本意说明最好. 实 际上 Davis 的准平原演化虽在开始强调坡地后退, 但到最后则产生高度降低, 而山麓面学说则 更强调山坡的平行后退. 试问退到最后是不是也要从高度上降低呢? 问题是不言自明的. 作 者认为, 无论是海蚀平原还是刻蚀平面和山麓面, 只要条件允许都可以看成是夷平面(也包括 准平原) 发育过程的一个阶段，只是在不同地区和气候条件下, 营力作用类型和速度不同而 已. 从理论上讲, 彼此之间实无不可逾越的障碍(图 1), 就像地球上各气候带之间并无“障碍” 
一样. 因此, 作者赞同多成因假说.

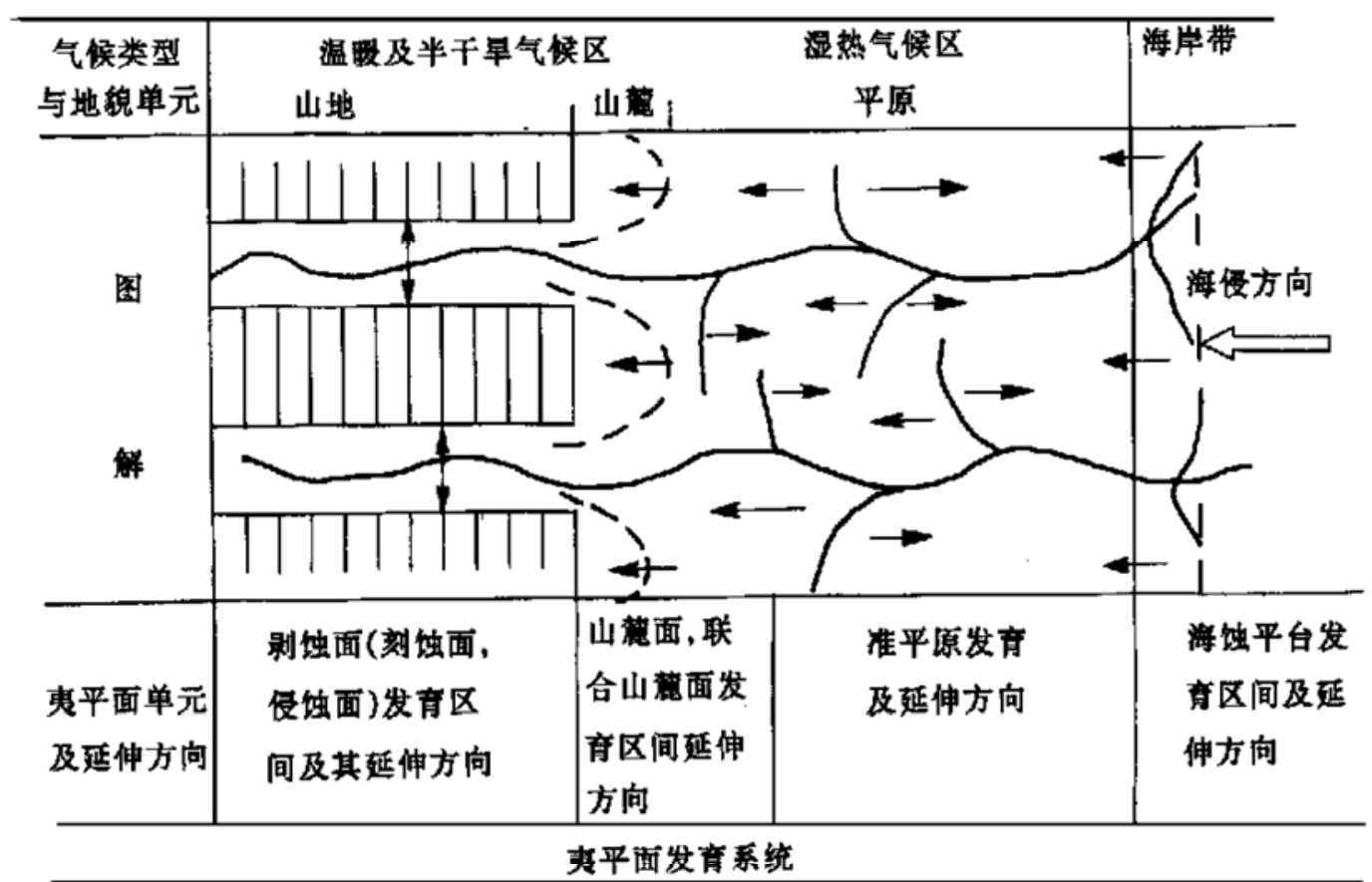

图 1 作者所理解的同一稳定构造-海侵旋回下夷平面发育系统框图

\section{2 研究现状}

近 30 多年来 (60 年代迄今), 所有大陆的夷平面都受到不同程度的研究, 就其结果而言夷 平面几乎无所不在. 1975 年 Adams 汇总了几十年来一系列夷平面研究成果, 并加以简述和删 节而出版了“夷平面——准平原、山麓侵蚀平原和刻蚀平原( Planation Surfaces: Peneplains, Pediplains and Etchplains) ”一书, 作为地质学标准文献之一, 足以反映夷平面在地貌学基本理 论中永恒的地位和作用. Fairbrige ${ }^{[15]}$ 教授为全系列书作了序言, 指出“地质学的标准文献 (Benchmark papers in geology) ” 就像测地图时的大地基准, 它们通常是做其他任何事情的要害 部分, 从历史角度看, 这些标准是建造科学大厦的“砖石”. 特别应该指出, 关于青藏高原隆升 问题在国际地学界兴起后, 夷平面研究立即引起国内外学者的关注. 早在 1983 年李吉均就指 出高原上夷平面的存在及其研究意义. Shackleton ${ }^{[16]}$ 也认为, 夷平面作为一个原始地面可以 是指示抬升的标志. $A d a m s^{[3]}$ 也提到可以把夷平面作为推测陆地抬升的依据. 但当时人们还 热衷于用古生物和古土壤发现时的高度与其现代生成环境、生成高度等对比( 虽然也加了某 些修正) 来判定隆升时代、幅度和速率等. 90 年代以来,一些国际同行提出, 古生物、古土壤等 是气候控制下的产物, 如果气候变了它们就可以出现在不同的高度. 因而这些数据证明不了 青藏高原上升的时间、幅度和速率. 这一看法提出后人们仍可持不同观点进行研究和争论, 但 也确实把如何寻找更可靠的关于高原隆升幅度和速率的无可争议的证据这一课题摆到了更明 显的位置. 实际是把“关于夷平面的研究在高原隆升中的作用和意义” 放到舞台中心, 因为地 层构造、断层、不整合面等地质现象也和古生物、古土壤的作用一样, 不能作为判断抬升幅度的 可靠标志. 海相地层当然是良好的标志层, 但高原上古老的海相层并不能作为抬升的证据, 而 
新海相层又未能发现. 就目前知识水平而言, 确業的夷平面及其可信的时代、高度、性质等是 唯一国际公认的判断陆地抬升幅度的证据. 因为夷平面的形成从全球角度看受控于海面侵蚀 基准, 而又与海侵事件相联系, 只有流域保持稳定的平衡剖面, 才能最终出现夷平面; 而从区域 看, 它的存在反映长时期 $(10 \mathrm{Ma}$. 左右) 的构造稳定. 同时，在热带亚热带气候条件下形成深 厚的风化层. 一旦该区抬升, 夷平面 (特别是上部风化层) 就将遭破坏. 从局部看, 地理位置 (离海远近等)、遭夷平地区岩性、地层结构等则可加速或减缓夷平的速度和强度. 为了满足全 球的和区域性的条件, 夷平面的发育就只能限定在一定的地质时期和一定的构造气候地貌区. 简言之, 夷平面开始发育区应在可接受海侵事件的影响范围内, 其海拔就不应太高. 但究竟多 高, 迄今无人断言. 目前可以追寻或勉强可以追寻的全球性夷平面多发育在中生代后期和第 三纪多个时段 ${ }^{17]}$ (图 2), 当时热带亚热带地区广布, 有大规模的海侵, 而在非湿热地区或受海 侵影响弱的地区则可发育较低级的平坦地形如山麓面和剥蚀面等.

1974 年美国地质学会东部分会曾专门讨 论了夷平面和夷平作用问题. 许多重要文章 来自澳大利亚、非洲、印度和欧洲, 这些研究涉 及原始准平原问题, 特别强调结构( structure)、 过程( process) 和阶段( stage) , 并把它与板块 运动 (plate tectonics)、海底扩张 (seafloor spreading) 相联系. 这对夷平面的研究无疑又 开辟了一个新的领域. 前几十年, 大部分有关 夷平面的研究内容都受到重视 ${ }^{[5,13,18 \sim 30]}$ 。而

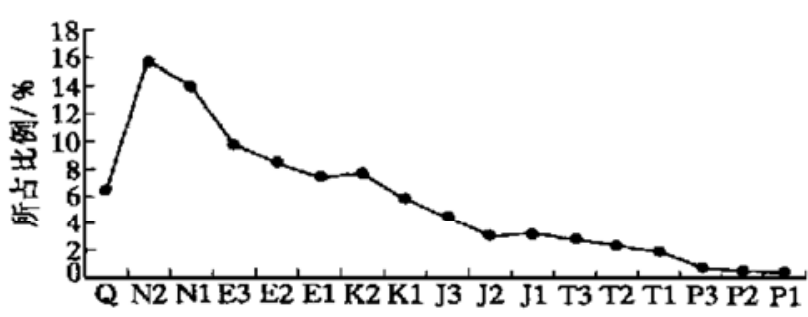

图 2 全球夷平面形成年代频率分布图

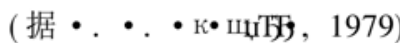
注意较多的则是两个方面: 一是从理论上研究夷平面的结构、形态、成因、分布与风化壳的形成 等, 约占 $1 / 3$ 比重强. 如 Budel ${ }^{[14,18,19]}, \mathrm{King}^{[25]}$ 和 Ollier ${ }^{[29]}$ 等人的工作; 二是不涉及理论而只 注意查明区域夷平面的有关级数、时代和对比等, 占 $1 / 3$ 弱. 其他方面则涉及夷平面的变形、 相关沉积以及夷平面研究史、动态, 结合持续发展的观点研究山区夷平面的生态保护和合理的 土地开发等. 而 1990 年 5 月在德国图林根由德国科学院形态动力委员会主持召开的“夷平面 形态动力学与形态成因”讨论会, 它的主要报告则反映了后来的欧美学者研究动态: 如“夷平 面上风化和风化壳”、“夷平面的形态成因” 和“夷平面及其扩展” 等. 中心议题是深部风化作 用. 看来自 Budel 1996 年提出“双层夷平面” 理论即强调风化在夷平面形成中的作用 ${ }^{[18]}$ (他 降低流水的作用一一作者注) 以来, 风化壳研究仍主导着夷平面的现代研究方向 (图 3).

前苏联学者和东欧学者的研究重点明显侧重于第 2 方面即区域夷平面特征和对比、相关 沉积研究等 ${ }^{[31,32]}$. 当然, 前苏联学者也有涉足于夷平面结构成因的, 而欧美学者也有热衷于 夷平面对比研究的(如英国、法国、澳大利亚、斯堪的纳维亚和巴西等).

我国学者近 30 多年来的研究, 亦涉及到前述夷平面研究的各个方面. 60 70 年代较多 注意夷平面的存在和一般的时代判定与对比 ${ }^{[33,34]}$, 多是从其他研究而涉及夷平面问题, 缺少 专门的研究. 80 90 年代, 注意力有所转移, 尤其是对云南夷平面变形的研究, 既持久而又比 较深入 ${ }^{[35 \sim ~ 37]}$, 并已开始注意到夷平面与高原隆升的关系和意义 ${ }^{[38,39]}$ 。作者则就青藏高原古 岩溶与夷平面的关系持续了近 30 多年研究, 对中新世夷平面的存在和年代以及灰岩区岩溶夷 平面的结构、成因及风化壳性质等基本理论问题, 取得了一些进展 ${ }^{[4]}$, 并日益认识到它对判定 


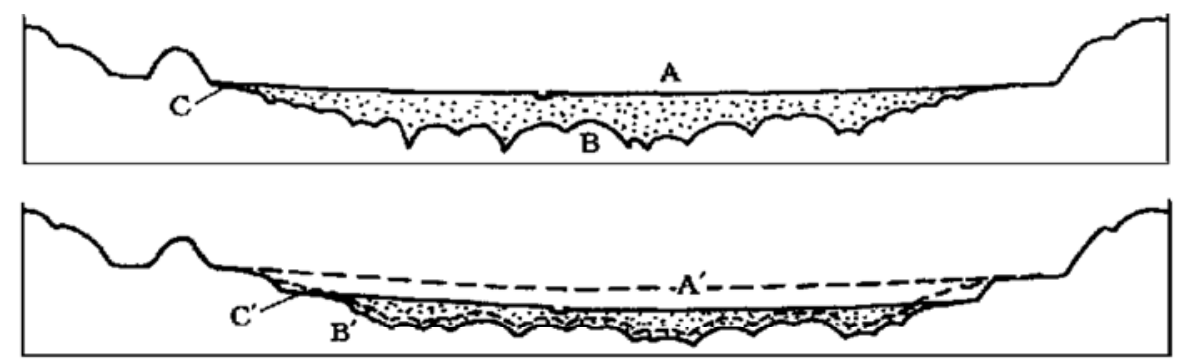

图 3 双层夷平面和山麓梯地

上图: 双层夷平面(热带水平面剖面). $\mathrm{A}$ : 上层面一冲刷面; B: 下层面一基部风化面; C: 冲刷山麓面. 下图: 向

下延伸的双层夷平面, 石质梯地的发展 一边缘冲刷山麓面. $\mathrm{A}^{\prime}$ : 降低了的上层面; $\mathrm{B}^{\prime}$ ：降低了的下层面

高原隆升时代、幅度、速率等方面的重要意义．同时, 吴忱等人 ${ }^{1)}$ 对华北山地夷平面和地文期 的研究, 在前人如 Willis、叶良辅和杨钟健对北台期准平原、鄂西期准平原等项研究的基础上, 发现甸子梁期夷平面并提出大量年代数据, 再次焕发出了“地文期”的原有光彩, 完善了自老第 三纪以来华北地文期系列, 着实壮大了我国研究夷平面的态势 ${ }^{1)}$. 总之, 我国夷平面研究有三 大特点, 分别填补了国际同行研究中的不足, 代表了夷平面研究的新方向: ( ) 对夷平面变形 的研究较国外深入、具体; ( ) 对夷平面年代的研究有新的贡献. 一是用裂变径迹法首次给 出了中新世夷平面的精确年代, 并提出了 “双层岩溶夷平面” 的概念, 作为对 Budel 理论的扩 展. 二是用 $\mathrm{K}-\mathrm{Ar}$ 法等给出了北台面、甸子梁面、唐县面等大量夷平面的年代数据; ( ) 明 确提出了利用夷平面研究高原隆升的幅度和速率等问题 ${ }^{4]}$.

\section{1 夷平面是什么样的?}

(1) 形态与高度. 人们谈论夷平面已经有很长的历史, 但它究竟是什么样子呢? Budel $^{[5]}$ 给了一个非常明确的回答. 他认为印度德干高地东坡面向 Coromandel 海岸地带, 即 介于斑加罗尔和马德拉斯之间的 Taimiland 平原 (平均海拔 $200 \mathrm{~m}$, 偶尔可达 $500 \mathrm{~m}$, 宽 100 $\mathrm{km}$, 局部达 $200 \mathrm{~km}$ ), 是一个现代夷平面的例子. 它和西侧高地 (斑加罗尔高平原, 海拔 750 $900 \mathrm{~m}$, 具有岛山, 最高可达 $1500 \mathrm{~m}$ ) 之间有一个 $100 \mathrm{~m}$ 高的陡坎. 过渡带还有两种起伏地 形, 即“热带山地地形” (被窄而长的河谷分割) 和“热带脊状地形” (由小的槽状沟, 小溪作浅状 冲刷而形成), 其中高的和较老的为前中新世形成, 那时热带气候较现在稍冷, 推测为“化石基 岩夷平面(fossilized rock peneplains)”。此处所说化石状态是指其被保存的含义, 它可以代表 由构造上升和深冲刷暴露的双层夷平面中的底面(即风化壳底面). 因上层面(风化壳顶面) 不 可能保存，而低的 Tamiland 平原则是一个具双层面性质的正在发育的夷平面.

(2) 岩性. 整个地区由花岗岩组成, 仅有少量沉积薄层和粗面岩脉穿插. 其实, 为使问 题简单化, 可以认为岩石抗风化能力是一个时间函数. 若夷平面上确有规模较大的高地存在, 则可以看成是前一旋回的侵蚀残留.

（3）地表坡度. 整个地面坡度不大于 $2 \%$ 或 0.6. 汇水的浅槽谷平均值为 $10 \%$, 最大 $20 \%$ $30 \%$ (1.2 1.7), 仅在平原上部边缘地区或远离河谷的岛山顶部坡度可达 3.5 4 .

1) 吴 忱. 华北山地地形面地文期与地貌发育史( 打印稿). 1996 
（4）红色风化壳和舌状岛山一夷平面必备的组成要素 红土层平均厚 $4 \sim 10 \mathrm{~m}$, 覆 盖整个地区, 是底部花岗岩风化的结果, 并沿着裂隙向底层延伸. 土下有坚硬圆形基岩突起存 在, 致使地表有一些不规则的起伏. 若基岩实起出露地表则成为“舌状岛山”.

(5) 现代地表地貌过程特点. 平原区整个地表红色风化壳缺乏任何侵蚀过程, 只产生化 学分解产物. 雨季时有小沟遍布平原并合并成较大的溪流, 然后形成河流. 但这些小溪和河 流仅搬运由化学分解提供的同样粒径的物质. 即包, 含高岭土和 50 $200 \mu_{\mathrm{m}}$ 的细砂. 河流本 身不能通过自身的侵蚀获得较大粒径的物质。总之这些不据侵蚀能力的河流只是搬运工具, 故他们只是水文单元, 而非地貌单元. 平原边缘和岛山山麓带坡折处因强烈化学分解作用而 有潜蚀并保持陡坡, 从而表明一个活动的夷平面仍在继续进行.

（6）与侵蚀基准面 (海平面)、构造运动的关系. 只要海洋侵蚀基准面保持稳定, “复制夷 平面作用机制”就将平行地蚀低这个地面. 并在所有方向上越来越平. 几乎没有构造抬升, 不 存在浅沟谷的切割.

(7) 斑加罗尔高平原形成时代. 斑加罗尔高平面形成于中新世以前, 持续了很长时间, 伴随着斑加罗尔地区的穹形隆起, 德干高原也在中新世成为穹状, 其隆升幅度向海岸方向减 弱. 斑加罗尔高平原由于沟谷的形成已被分割, 形成阶梯状地形, 并逐渐变成老的基岩夷平 面.

（8）夷平面形成的气候条件. 为热带季风气候和热带稀树草原气候.

\section{2 关于夷平面原始高度的讨论}

上述各点中最有意义的是关于夷平面的原始高度. 从理论上讲, 文献 [ 40] 早已提到, 就海 陆地形因剥蚀堆积而形成的宏观地势而言, “上升了的(海进的) 海洋水准面与降低了的陆地 水准面会在某一个等高线上相遇. 这个等高线将是位于距海洋原始水准面较近, 面距陆地原 始平均高度较远的地方 (因为海洋体积比陆地的大)”. 彭克算出, 这两个水准面将相遇于海洋 水准面上 $250 \mathrm{~m}$ 的地方. 在此之后, 剥蚀就被阻止了. 因为陆地水准面已降低到剥蚀基准面一 海洋水淮面上了. 彭克把这个水准面叫做坚硬地壳与液体地壳的界面. 马尔科夫就把它理解 为剥蚀基准面 ${ }^{[40]}$. 作者认为这也应该是原始夷平面的理论高度, 它可以再高些, 也可能再低 些. 如印度 Taimiland 平原平均海拔 $200 \mathrm{~m}$, 我国华北山地的山麓面也比较低 $(100 \sim 200 \mathrm{~m})$.

从实际材料看, 华北地区中、上新世的三趾马动物群与西藏的三趾马动物群在性质和地层 层位上可以对比, 海拔和生态环境相近, 若两地同为发育三趾马红土的统一夷平面, 则其原始 海拔高度应在 500 $1000 \mathrm{~m}$ 左右或更低. 据云南夷平面古红土分布规律, 联系到青藏地区在 上新世一般高为 $1000 \mathrm{~m}$, 估计云南在西北隅亦应为 $1000 \mathrm{~m}$, 而大部分在 $500 \mathrm{~m}$ 上下 ${ }^{[4]}$. 据 古生物资料, 川西上新世夷平面海拔亦仅 $1000 \mathrm{~m}^{[42]}$.

据红土风化壳原始发育高度 $(200 \sim 500 \mathrm{~m}$ ) 以及岩溶发育高度等认为取 $500 \sim 1500 \mathrm{~m}$ 的 中值, 即 $1000 \mathrm{~m}$ 为夷平面的原始高度为好 ${ }^{35]}$. 现代印度 $\mathrm{T}$ aimiland 平原 $(200 \sim 400 \mathrm{~m})$ 海拔 亦低于 $500 \mathrm{~m}^{[5]}$. 陆景冈 ${ }^{[43]}$ 还认为铝土矿就是脱硅富铝化的古土壤, 也是热带亚热带夷平面 发育的产物, 在我国它们的分布多贴近潮湿和地势较低的海岸线. 铝土矿几乎与古红土共生, 分布也一致,多在新构造升沉过渡区, 海拔仅 50 $200 \mathrm{~m}$. 也有遭高原抬升而达到 1200 (贵 州) 和 2000 以上(云南) 者. 


\section{3 夷平面活动状态及其分类}

研究夷平面时, 应查明形成它的外营力是否仍在继续作用, 即形成夷平面的同一旋回是否 仍在进行中. 此外, 还应特别关注形成该面的夷平作用的结束时间. Adams ${ }^{[3]}$ 认为, 可以从这 一角度对夷平面进行分类, 在经作者补充后, 简列如下:

(1) 活动面 (active surface). 迄今仍在进行活动的夷平面. 如 Budel 所指的印度德干高 地东坡的面. 时代是全新世迄今.

(2) 休眠面 (dormant s. ). 也许因为气候变化而暂时停止活动并有望在将来(地质时间 尺度) 重新活动的面. 时代在早更新世与全新世之间.

(3) 外来面 (exotic s.). 一个形成于非现代气候条件下的面. 而当时的气候已不能肯定 会再次发生, 时代没有限制. 如青藏高原的主夷平面( 中、新世中晚期).

(4) 废止面( defunct s. ). 一个因抬升、下沉或气候变化而脱离了夷平作用的面. 时代也 许是三叠纪 全新世.

(5) 埋藏面 (buried s.). 一个被与其无关的沉积物覆盖、保护或被熔岩流封闭起来的面. 可以通过钻孔、采矿或沟谷侵蚀等暴露出来, 也可用地球物理方法查明其存在. 其时代范围从 前寒武纪到三叠纪. 在中国北方和西北可以是老第三纪. 如天山地区最低一级夷平面 (1800 $\sim 2500 \mathrm{~m}$, 面上有 $2 \mathrm{~m}$ 厚的风化壳) 在其南麓铁门关一带即被上覆渐新统、中新统沉积层所 覆盖、保护 ${ }^{1)}$.

（6）剥蚀面或化石面( exhumed or fossil s. ). 移走无成因联系的后来的沉积物或盖层, 使 埋藏面部分暴露出来, 再遭受切割, 如青藏高原及云贵一带的主夷平面也可能属此类型.

由以上不同角度的分类来看, 我国现存的或残存的夷平面, 如青藏高原及云贵一带的主夷 平面、华北山地的北台面都具备多种属性, 它们既是上述的化石面、废止面和外来面, 在某些地 段也可以是埋藏面. 然就青藏高原现存主夷平面而言, 实际上还存在着一种不同夷平作用在 同一面上进行的夷平面, 此可谓叠置面( overlap s.).

(7) 叠置面. 如形成于中新世湿热气候下的主夷平面, 在抬升后又遭到第四纪以来的寒 冻风化的剥蚀夷平, 即冰缘环境下的高夷平作用(Altiplanation). 安多北山(拉惹山5 $125 \mathrm{~m}$ ) 平坦的山顶面上有残留红色风化壳, 其上部已被寒冻风化碎屑层所覆盖, 但山顶仍保持非常平 坦, 现在实际上是一片石海.

Adams 的分类, 看似繁琐, 但反映了西方同行对夷平面的研究有其深入细致的一面.

\section{4 几点结论}

（1）不同单元不同类型的夷平面确实存在, 不是任何偶然的地貌过程的产物. (2) 最易确 认的夷平面单元是山麓面和联合山麓面，最不能确定的是严格定义的准平原．最不易区分的 是局部的准平原和刻蚀平原. (3) 由于抬升或是埋藏，夷平面最重要的时间特征是: 所形成的 侵蚀循环开始的最晚可能时间到停止发育时的最早可能时间(它的终结时间)。(4) 在试图从 当前夷平面的海拔高度推断大陆隆升时，要考虑它们的成因和形成环境、基准面(初始海拔高 度) 和可能的区域坡度 (比降), 正象作者在研究青藏夷平面及其和高原隆升的关系所做的那 样 ${ }^{[4]}$. (5) 夷平面在最初发育时, 不需要相同的气候体系. 不同类型的风化壳是夷平面的组

1) 王树基. 天山夷平面上的晚新生代沉积及其所显示的环境变化. 见: “人类与环境” 第四纪委员会编, 第七届全国第 四纪学术会议文摘要. 1997 
成部分, 但风化过程早于发育夷平面时的侵蚀循环. (6) 根据某些基本高程, 通常的海平面及 海平面以上的内流盆地和气候控制等可以给夷平面分级. 但高低位置不表示夷平面年代, 最 老的可以在高处, 也可以在低处; 最新的亦然. 但从理论与实践上看, 在抬升的山地和高原, 老 的夷平面只能比新的更高. (7) 从全球看, 发育夷平面的侵蚀循环与较大规模的海侵有关, 故 夷平面研究应纳入与板块构造学、海底扩张说和不同气候区的大陆变化的统一框架内. 这也 正是夷平面研究中较前人有所创新的领域.

\section{3 今后研究的主要问题}

\section{1 夷平面的结构和成因、类型}

Budel $^{[18]}$ 提出双层夷平面后, 虽获得相当支持, 但并未获公认. 如法国著名的气候地貌学 家 Tricart ${ }^{[4]}$ 就认为他太理论而不予支持. Ollier 虽然支持但也有一定保留, 因为 Ollier 在乌 干达夷平面演化中只看到一个长的深度风化时期, 并无多个循环周期. 作者以青藏 川西 滇 黔 桂一线覆盖岩溶发育与演化事实为例, 支持 Budel 的理论. 它确实很好地启发作者 解决了难以解决的问题. 因为上述一线灰岩地区所暴露的侵蚀面上, 有许多地貌现象不是气 下过程所能解释的, 而应是地下过程的产物. 这些面只是抬升-剥蚀后从地下风化面暴露出来 而转化成为现在的剥蚀面, 即原来的下层面变成了现在的上层面. Budel 的理论允许这个风化 盖层被完全剥露并呈现不规则的风化表面, 如青藏高原主夷平面上安多北山出露有各种大型 石芽起伏的风化面. 中国湘桂一带灰岩区上层风化面和下层风化基岩面也同时存在, 可见, 应 加强夷平面现代过程和解剖古夷平面的研究. 在中国就湘 桂 黔 滇 藏一线灰岩区双层 夷平面的结构、演化及其与高原隆升的耦合关系进行解剖, 将丰富和深化夷平面的研究内容.

\section{2 夷平面的原始海拔高度}

应尽量统一认识夷平面的原始海拔高度到底可以有多高. 除 Budel 所指出的印度德干高 原东坡 T aimiland 仍在活动的夷平面外, 还应利用现代手段如卫片、GPS 和现场考察等手段进 行追寻, 以便发现更多的依据可以作为“将今论古”之用. 虽然公认活动的夷平面不会离海面 太高, 但最好能通过各种可以反映海拔高度的标志, 如与动植物、土壤和岩溶等有关的气候地 貌过程, 确定一个可接受的高度范围, 如 200 $500 \mathrm{~m}($ ? ) 或大于 $500 \mathrm{~m}($ ?).

\section{3 提高夷平面定年精度、进一步深化对夷平面变形的研究}

一个夷平面就代表一个时代, 是地貌学上最好的“地层” 标志 ${ }^{1)}$, 应提高分辨率以完善确定 夷平面时代的各种间接推定法, 扩大和完善直接测定法, 如裂变径迹法和 ${ }^{10} \mathrm{Be}$ 法. 后者的原理 是测定基岩或漂砾中所含石英颗粒接受太阳暴晒后的剂量变化 ${ }^{[45]}$, 完全可以应用于夷平面年 代研究, 只要所测年限可以延伸到 $10 \mathrm{Ma}$ 以上. 若能将此法与利用火山岩同位素测定岩体年 代结合起来, 就可获得岩体在地下和暴露后的年代, 其差值则应是夷平面形成的时段. 只有年 代可信, 对比才有意义.

夷平面的对比应分为两个级别, 即全球性的对比和区域性对比, 并分别确定对比的标准. 前者抓大节, 后者管小节. 不可搞乱级别和序次, 否则毫无意义. 对夷平面变形的研究, 也应 作为研究特点而更具体地展开.

夷平面的全球对比难度很大, 但应该是可能的, 因为夷平面发育与全球性海侵相关. 就中

1) 是“抽象”的地层, 不是具象的地层 
生代以来的地质历史面言，第四纪和现代可以看成是比较大的海退时期，因为此时海水加深 和陆地隆起非常强烈, 而中生代后期和第三纪则应是比较大的海进期 ${ }^{[40]}$. 事实上, 现在所查 明的各地区的夷平面也都在这一时段(图 2), 而在古老的地质历史中也有相应的例子. 如根 据沉积建造和共生矿产方面的研究, 我国华北地区中奥陶世 石炭纪期间, 广大溶蚀平原及其 红土风化壳亦即铝土矿 (主要赋存于岩溶洼地中) 和夷平面的发育就是和海侵事件相联系的, 其间共经历了 1 亿 4 千万年的长期剥蚀、风化和夷平 ${ }^{[46]}$. 夷平作用只有通过全球夷平面对 比, 才可望与板块运动、海底扩张及古大陆变化等宏观过程联系起来.

为了给夷平面对比提供可靠的依据, 应开展夷平面制图工作, 用统一图例编制典型区的夷 平面图, 内容包括面积、级数、结构与风化壳类型、高度、时代、岩性、变形方式、切割地层与构 造、相关沉积等. 夷平面制图工作的重要性不仅见于地形和缓的高原地区, 即使在山区也常见 到大面积分布的夷平面. 例如在中亚山地 (外伊犁阿拉套、准噶尔阿拉套、阿尔泰山等), 夷平 面占有可观的地位, 面积比例平均为 $17.2 \%$, 在阿尔泰山达 $24 \%{ }^{[47]}$.

\section{4 夷平面与风化壳的研究}

Budel $^{[5]}$ 和作者都主张双层夷平面理论 ${ }^{[4]}$ ，即视上层( 风化) 面和下层 (风化基岩) 面是一 个整体, 风化壳表层冲刷和底部的延伸应保持同步而达平衡. 也有人主张基岩夷平面先形成 上面再发育风化壳. 这两种情况是否同时存在? 在 1990 年德国图林根讨论会上, 就有人提 出，夷平面上底部风化过程和表面物质迁移，在时间上同时发生还是交替进行? 现代夷平面 发育过程是否还在进行? 这些问题有待深入研究.

此外, 正如陆景冈 ${ }^{[41]}$ 所提出的, 在冈瓦纳古大陆分裂后的古夷平面上( 应是中三叠或晚 侏罗早白普世夷平面) 有铝土矿分布, 它们也多分布在热带亚热带地区, 实际上是古风化壳在 第三纪以来的夷平面上形成铝土矿. Thomas ${ }^{[48]}$ 在通过大量的钻孔和地面观测研究尼日利亚 结晶岩深度风化层时, 曾引用 Ollier 的观点, 认为乌干达风瓦纳面下的深度风化层发育于中或 早第三纪, 他还进一步强调大多数热带非洲的深度风化早于近期的侵蚀旋回. 这一点很重要, 因为从理论上讲, 只要有地面存在就有风化, 故风化早于侵蚀旋回是完全合理的.

这里强调了风化作用, 而河流在夷平面形成过程中的作用应如何恰当地评价? 这个问题 以前被强调现在则被忽视, 特别在所有说是先成河的地段, 如喜马拉雅山、横断山区、金沙江、 长江三峡区等. 因此, 应在夷平面上加强寻找古河道的工作.

\section{5 对各级夷平面进行综合研究}

从地貌学、地质学、土壤学等进行综合研究, 并与人民生产、生活、土地开发等联系, 作专门 图件, 这对景观与环境的研究和保护, 改善土地利用情况等有重大意义. 据了解巴西联帮州和 我国华北山地已开展此项研究. 特别是外生矿产的形成, 如铝土矿等与夷平面形成几乎是一 回事. 据西伯利亚及北哈萨克斯坦白严纪和老第三纪夷平面成壳期与铝土矿堆积期的区域对 比研究发现, 每一区域性的铝土矿沉积旋回可以对比于一级夷平面 ${ }^{[49]}$.

总之, 从 60 70 年代以后近 30 余年, 夷平面研究在空间上、内容上和方法上是扩展了, Adams 主编的“夷平面”一书 ${ }^{[3]}$ 的出版可以看成是一种“呼唤”. 也许正在酝酿着继 1890 1910 年研究高潮和 1950 1970 年第 2 次高潮以后的第 3 次高潮(下世纪 10 20 年代?).

致谢 感谢施雅风先生对本文的支持和帮助. 


\section{参 考 文 献}

1 Davis W M. The peneplain: geographic essays. Boston: Ginn and Co, 1898( rev. 1909). 350 380 ( sec pager 3)

2 Gilbert G K, The convexity of hillslopes. J Geol, 1909, 17: 344 350

3 Adams G. Planation Surfaces, Dow den, Hutchinson \& Ross, Inc Strouds burg. Pennsylvania: Halsted Press, 1975

4 崔之久, 高全洲, 刘耕年, 等. 夷平面、古岩溶与青藏高原隆升. 中国科学, D 辑, 1996, 26(4)：378 385

5 Budel. The relief types of the sheetwash zone of Southern. India on the Eastern slope of the Deccan Highland Tow ard Madras, 1957

6 Ramsey A C. The denndation of South Weeles. Mem Geol Surv Gt Brith 1, 1846, 197 235

7 Davis W M. The physical geography of southern New England. Natl Geogr Soc, Monograph, 1896, 1: 269 304

8 Davis W M. The scheme of the erosion cycle. J Geol, 1923, 31: 10 25

9 Penck W. Die morphologische Analyse. Engelhorn Stuttgare, 1924. 283

10 Davis W M. Basal_level, Grade, and peneplain. Jour Geol, 1898, 10: 77 111

11 Brown E H. Britain and Appalachia: a study in the correlation and dating of planation surfaces inst. Brit Geogr Trans, 1961, 29: $91 \sim 100$

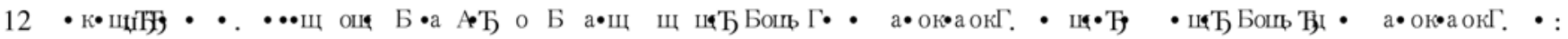
$\cdot \mathrm{a} \bullet \mathrm{a}, 1964.65 \sim 75$

13 King L C. Morphology of the Earth. Edinburgh_London, 1962,

14 Baulig H. Peneplains and pedplains. Bull Geol Soc America, 1957, 68: 913 930

15 Fairbridge Rhodes W. Series editor's preface(for Benchmark papers in geology: Planation Surfaces). Dow den, Hutchinson \& Ross, Tnc: Halsted Press, 1975

16 Shackleton R M, Chang C F. Cenozoic uplift and deformation of theT ibet Plateau: the geomorphological evidence. In: The Geological Evolution of the Tibet Plateau (Chang C F, ed. in Chinese). Beijing: Science Press, 1990. 372 383

17 ・

18 Budel. Die "Doppelten Einebnungsflachen "in den die feuchten Tropen. Zeitsch F•r Geomorph Ologie, 1957(2): 201 228

19 Budel. Die Flachenbildung in den feuchten Tropen und die Rolle Fossiler solcher Flachen in anderen Klimazonen. Verhandl Dtsch Geographentag, 1958, 31

20 Budel J. Klima_genetische Geonorphologie. Geogr Rundshau, 1963, 7: 269 286

21 Cotton C A. Peneplanation and pediplanation. Bull Geol Soc, 1955, 66: $1213 \sim 1214$

22 Cotton C A. Plains and inselbergs of the humid tropics. Trans Roy Soc, 1962, 88: 269 277

23 Cotton C A. The theory of savanna planation. Geography, 1965, 46: 89 101

24 King L C. The study of the world's plainlands: a new approachto geomorphology. Quart J Geol Soc, 1950, 106: 101 127

25 King L C. The morphology of the earth, 2nd ed. Hafner, New York, 1967

26 Klein C L. Surfaces polygeniques et surfaces polycycliques. Bull Assoc Geogr Franc, 1959, 282 283

27 Lefevre M A. Surfaces d' aplanissement et niveaux d' erosion. Tijdschr.-Koninkl Nederl Aardrijkskund Genootschap, 1957, 74: 3

28 Ollier C D, Tuddenham W G. Inselbergs of Central Australia. Zeitsch F•r Geomorph Ologie, 1961(4)

29 Ollier C D. Weathering. American Elsevier. New YorK, 1969, 304

30 Simons M. The morphological Analysis of landform. a new review of Penck's Work. Tnst Brit Geogr Trans Paper, 1962, 31 : 1 4

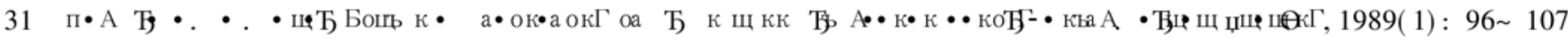

32 •а окщ ・ п. • ЂокБ шъ Бощ к

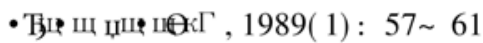

33 黄培华. 云南新构造运动特点与大地构造关系. 南京大学学报. 1959. (7)：51 64

34 沈玉昌. 长江上游河谷地貌. 北京: 科学出版社, 1995

35 何浩生, 何科昭. 滇西地区夷平面变形及其反映的第四纪构造运动. 现代地质, 1993(7)：31 59

36 陈富斌, 陈继良, 徐毅华, 等. 玉龙雪山-苍山地区第四纪沉积与层状地貌的新构造分析. 地理学报, 1992, 47( 5)：430 440

37 何科昭, 何浩生, 蔡红欵. 滇西造山带的形成与演化. 地质论评, 1996, 42(3)：97 106 